\title{
Testing Social Media Advertisements for Animal Advocacy
}

Christopher Bryant ${ }^{1}$, Brian Platt ${ }^{2}$, Anthony Vultaggio ${ }^{2}, \&$ Courtney Dillard ${ }^{2}$

${ }^{1}$ Bryant Research Ltd, United Kingdom

${ }^{2}$ Mercy For Animals, United States of America

DECEMBER 2021 


\section{Executive Summary}

We used the Mercy For Animals social media outreach budget to systematically estimate the efficacy of different advertisements on different demographic groups. Based on the click-through rates (CTR: the percentage of impressions resulting in clicks on ads), we observe:

1. Animal-based advertisements are more than twice as effective as other types of advertisement, achieving a CTR over 3\% compared to just $1.1-1.5 \%$ for environment, health, and social adverts.

2. Females and older users were more likely to click adverts compared to males and younger users, respectively.

3. Specific messages may outperform others within these broad themes. We find that pigs were the most effective animal advert (vs. cows, chickens, and fish), climate change was the most effective environment advert (vs. land use, water use, and deforestation), and chronic disease was the most effective health message (vs. obesity, pathogen contamination, and antibiotic contamination).

The findings can be used to inform social media strategy for Mercy For Animals and the broader animal protection movement. 


\section{Background}

Research on the efficacy of different veg*n advocacy messages has proliferated in recent years, yet there are still significant gaps in our knowledge. Experimental evidence has tended to suggest that animal cruelty messages are more effective at reducing animal product consumption than health- or environment-based messages (Faunalytics, 2012; Humane League Labs, 2014; 2015). However, the details of these different impacts, as well as differential impact for different specific messages within these broad themes, remain relatively unexplored by researchers.

Moreover, many existing studies rely on participants self-reporting dietary change or intentions, and therefore are subject to response biases. In particularl, social desirability bias which is known to be an issue in this area of research (Humane League Labs, 2018). Furthermore, some studies sacrifice ecological validity for experimental control, asking participants their preferences in settings which allow for tightly controlled messages, but may be too contrived to represent real consumer decision situations (Humane League Labs, 2018).

Social media testing represents an excellent opportunity to address these shortcomings of previous animal advocacy research. Unlike survey responses which can be contrived, whether somebody clicks an advert is a more direct measure of their interest in the message, and an outcome which is directly applicable to the aims of animal advocacy. Social media testing also allows researchers to precisely define messages and audiences, testing different approaches for different segments. This is a useful feature for testing animal advocacy messages, since some evidence suggests that younger people tend to be more receptive to ethical or environmental appeals, whereas older people tend to be more interested in health-based messages (Pribis, Pencak and Grajales, 2010).

Mercy For Animals has previously engaged in some form of social media testing, reporting on the features of posts which were most likely to be shared and viewed by many people (Rouk \& DeFries, 2018). However, this was limited to optimising shares and impressions rather than engagement with a request, and was based on making content to be shared rather than paid advertisements. This research project will utilise Mercy For Animals' existing social media budget to investigate which messages on paid adverts result in the most engagement for which audiences. 


\section{Approach}

\subsection{Procedure}

We compared the performance of four different Facebook ad campaigns relating to animals, health, the environment, and social norms. Each campaign had a budget of $\$ 500$, and targeted audiences across age/sex groups who were not existing supporters of Mercy For Animals directly or through their Facebook page. Therefore, the audience represented a broad segment of society, excluding MFA supporters.

\subsection{Measures}

Here, we compare several outcome measures:

1. Reach. The number of unique viewers exposed to the advertisement.

2. Impressions. The number of times an advertisement is viewed, including double viewings by the same individual.

3. Clicks. The number of times the advertisement was clicked.

4. Results. The number of times the advertisement lead to a successful outcome (in this case, signing up to an email list).

We also combine some of these outcome measures to get a picture of overall efficiency. This includes click-through rate (CTR), defined as the percentage of impressions which result in clicks. Similarly, conversion rate (CVR) refers to the percentage of clicks that end up producing the desired result. CTR and CVR, therefore, are measures of ad effectiveness which can be applied across different audience sizes.

\subsection{Materials}

We tested 12 adverts related to 4 topics: animals (cow, pig, chicken, fish), environment (climate change, deforestation, water use), health (chronic disease, pathogens, antibiotics, obesity), and social (social norm). The full contents of the advertisements are shown in Appendix $A$. 


\section{Evaluating messages overall}

In the first instance, we evaluated the performance of the ads overall.

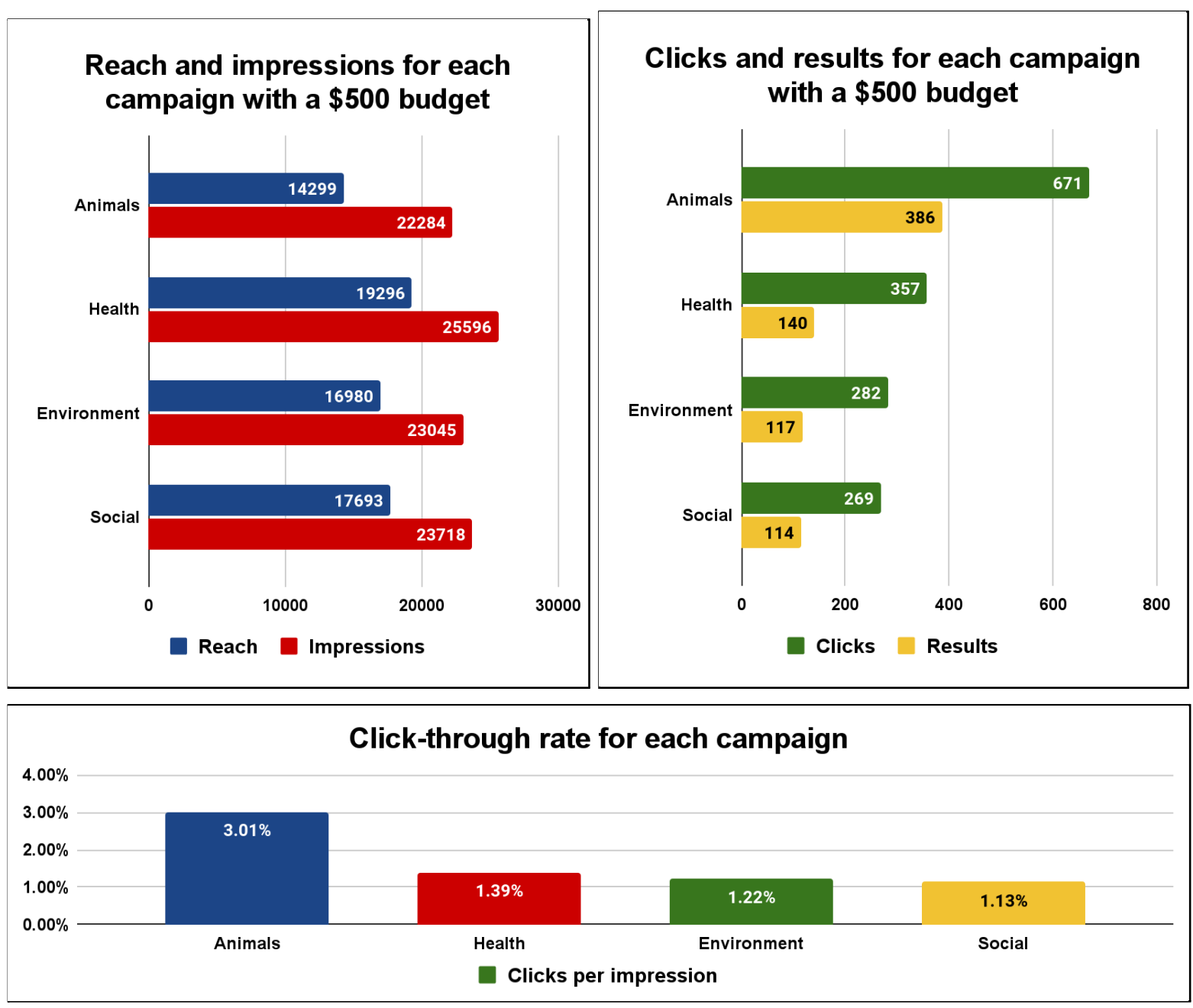

As shown, the advertisements with images of animals achieved the lowest reach and impressions, even given the same budget. It may be that people are more likely to avoid these images, causing fewer people to interact with the posts and therefore less second-hand exposure to audience members' friends.

Despite this, the images of animals also achieved the highest number of clicks and results, with approximately double the number of clicks compared to the next-most-clicked link despite the lower reach.

The animal advertisement had the highest CTR, with about $3.0 \%$ of those who saw the animal advert clicking on it, compared to just $1.1 \%-1.4 \%$ of those who saw the other adverts. The animal advertisement also had the highest conversion rate, with about $58 \%$ of those who clicked also signing up to the mailing list, compared to just $39 \%-42 \%$ of those who clicked on the other adverts.

Together, these results show that the animal campaign was far superior to the other campaign amongst this audience. Despite having a lower reach and fewer 
impressions, this campaign still achieved the best results due to a far higher CTR, and a somewhat higher CVR.

\section{Promising messages \& demographic groups}

We also investigated the effectiveness of the different messages across different demographic groups. For these analyses, although the advertisement sets received the same budget, the specific advertisements within the sets were shown in different quantities to different groups due to Facebook advertising's automatic prioritisation of high-performing ads. Therefore, we only report here the CTR, which is therefore comparable across advert sets despite different audience sizes.

The technical analysis here was performed using multiple linear regression. The dependent variable was CTR, and predictor variables included age, gender, and dummy variables for advertisement sets relative to the reference set (social ads). This method can identify demographic features and advertisement sets which were associated with a higher CTR.

As shown in the regression table, these variables accounted for $28 \%$ of the variance in CTR, suggesting that they had a significant effect on advertisement success. As shown, factors associated with higher CTRs included being female, older, and seeing advertisements depicting animals.

\begin{tabular}{|l|l|l|}
\hline \multicolumn{3}{|l|}{$F(5,114)=10.321, p<0.001$} \\
$R^{2}=0.312$, Adj $R^{2}=0.281$ \\
\hline Variable & Std. $\beta$ & $p$ \\
\hline Constant & & 0.114 \\
\hline Gender* & 0.261 & 0.001 \\
\hline Age $^{*}$ & 0.191 & 0.016 \\
\hline Animals* & 0.476 & 0.001 \\
\hline Environment & 0.015 & 0.911 \\
\hline Health & 0.029 & 0.837 \\
\hline
\end{tabular}

* indicates the variable is a significant predictor of CTR at $p<0.05$

We can represent this more intuitively in a graph. In this graph, we see the advert topics represented in the bar outline colours, and age and gender represented as the colour of the solid bars. Younger groups are represented in lighter colours, older groups in darker colours, and males and females are represented in blue or red respectively. 


\begin{tabular}{|c|c|c|c|c|}
\hline Animals & Envir & ent & Health & Social \\
\hline M18-29 & M30-39 & M 40-49 & M50-59 & M60+ \\
\hline F18-29 & F 30-39 & $F 40-49$ & F 50-59 & F60+ \\
\hline
\end{tabular}

\section{Click-through rate for each campaign/group}

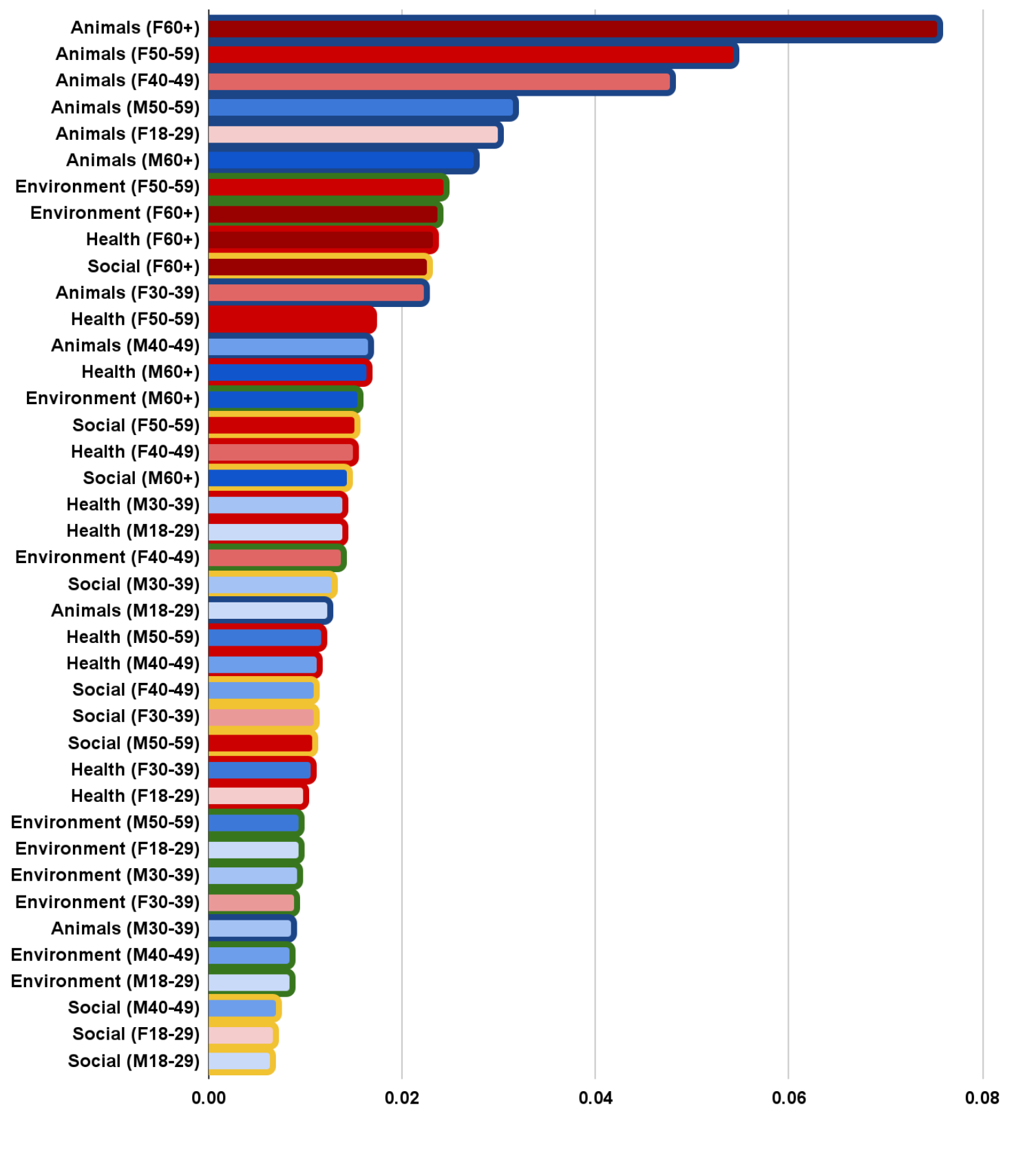

We can see a relatively high density of darker colours and reds towards the top of the graph, indicating that older groups and female groups are amongst the most likely to click ads, while younger people and males are amongst the least likely. We can also see that animal-related adverts tended to be concentrated towards the top 
of the graph, indicating that animal adverts were the most effective across most groups. In combination, the ad set with the highest clickthrough rate by far was animal adverts shown to females over the age of $\mathbf{6 0}$ - more than $7 \%$ of these cases resulted in an ad click, compared to an overall average of about $1.5 \%$.

\section{Detailed ad content}

In this section, we grouped all of the ads together, and compared CTRs between specific groups across all other conditions. The main purpose was to compare the more detailed ad content within the categories of animal, environment, health, or social messages. We first verify and demonstrate this approach by showing the ageand gender-based differences in CTR shown above.

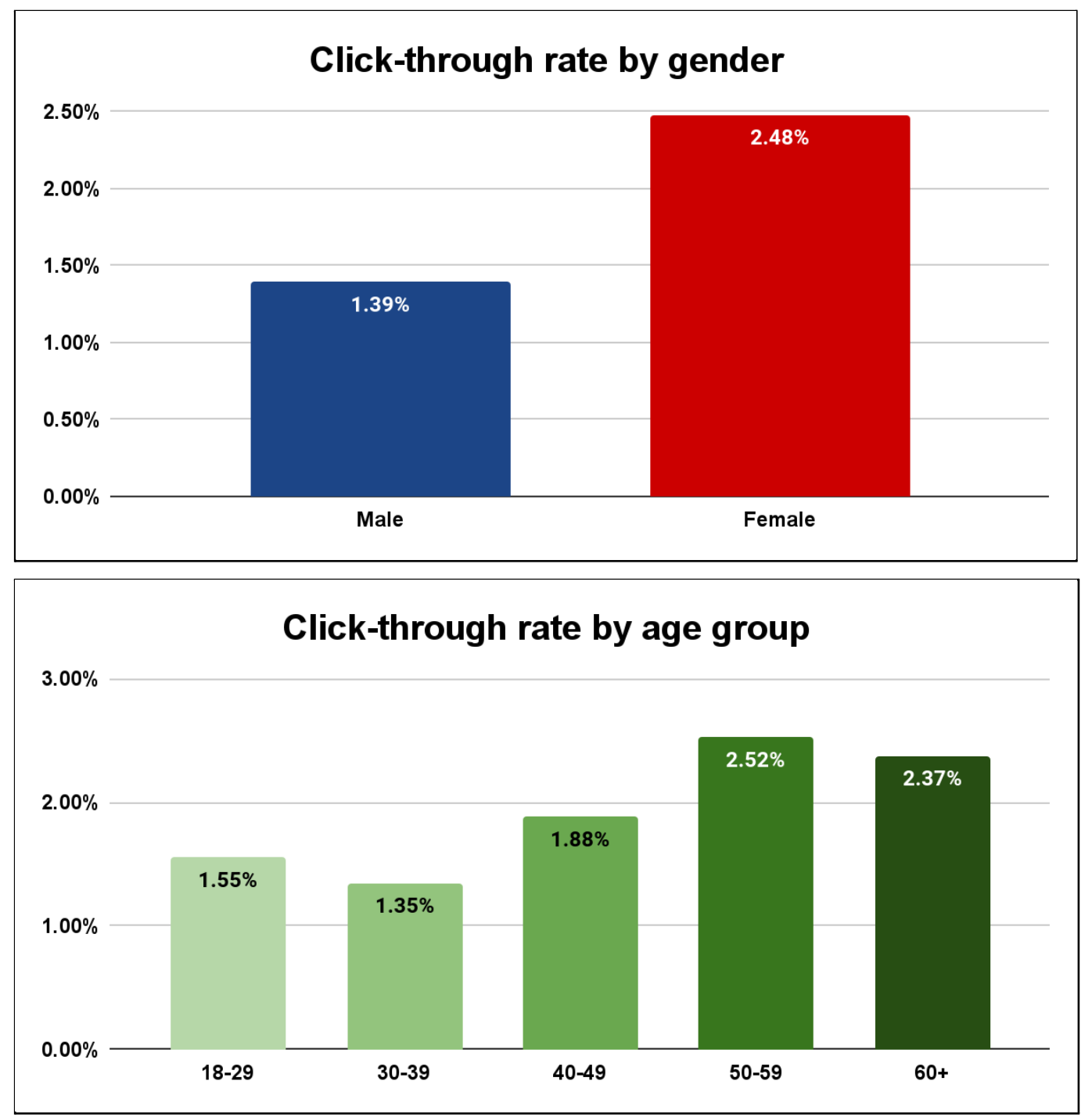

As shown, we can demonstrate the higher CTRs for females and older people.

Using ANOVAs, we determined that these differences were statistically significant for gender $\left(F(1,118)=8.597, p=0.004, \eta^{2}=0.068\right)$ but not for age groups $(F(4,115)=1.431$, $\left.p=0.228, \eta^{2}=0.047\right)$. 
Below, we show the click rate by each ad set, and by the specific content of each ad.
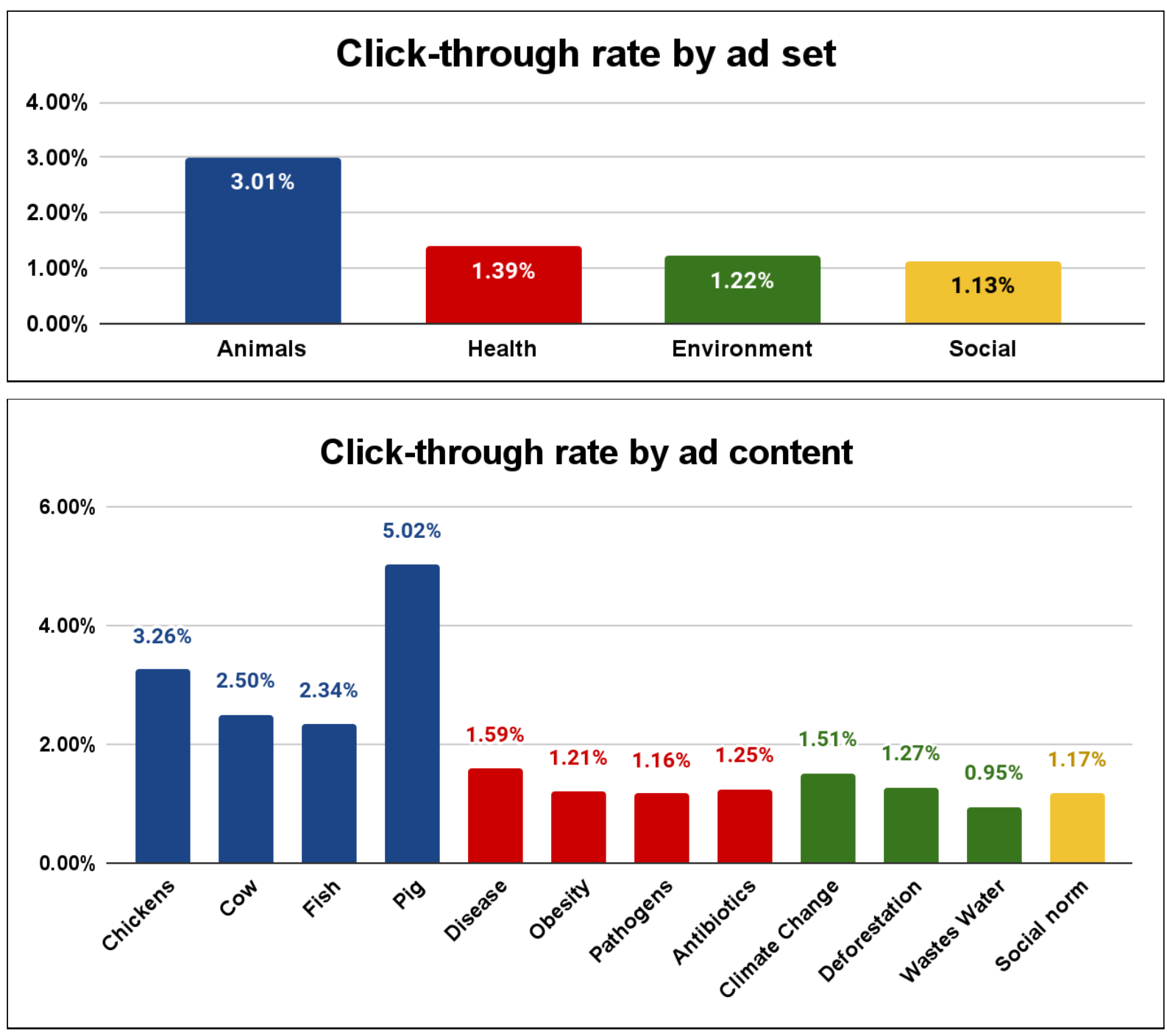

Within each set of advertisements, we can see that the pig was the best-performing animal message, climate change was the best-performing environmental message, and chronic disease was the best-performing health message.

ANOVAs demonstrated a significant difference based on advertisement set $\left(F(3,116)=10.114, p<0.001, \eta^{2}=0.207\right)$, and specific advertisement content $\left(\mathrm{F}(11,108)=4.188, \mathrm{p}<0.001, \eta^{2}=0.299\right)$.

\section{Conclusion}

Overall, these analyses suggest that social media adverts for animal protection should prioritize an animal message over health, environment, or social messages, and should favour targeting females and older users. We hope these findings will be useful for the broader animal protection movement. 


\section{References}

Faunalytics. (2012). What is the Most Effective Veg Outreach Video? Faunalytics. Available at https://faunalytics.org/what-is-the-most-effective-veg-outreach-video/

Cooney, N. (2014). What elements make a vegetarian leaflet more effective? Humane League Labs. Available at https://osf.io/nwcgf/

Doebel, S., Gabriel, S., \& Cooney, N. (2015). Report: Is Animal Cruelty,

Environmental or Purity ("Abolitionist”) Messaging More Effective At Inspiring People To Change Their Diet? Humane League Labs. Available at https://osf.io/yw9nm/

Peacock, J. (2018). Measuring Change in Diet for Animal Advocacy. Humane League Labs. Available at

https://assets.ctfassets.net/ww1ie0z745y7/1sHurac1JzOOSMwlunl8fH/dda7c264e30 e71cc8499ff1d9f190f8c/E009R01-measuring-diet-animal-advocacy.pdf

Pribis, P., Pencak, R. C., \& Grajales, T. (2010). Beliefs and attitudes toward vegetarian lifestyle across generations. Nutrients, 2(5), 523-531.

Rouk, S. \& DeFries, N. (2018). How to Dominate Social Media. Mercy For Animals. Available at https://mercyforanimals.org/blog/dominate-social-media 


\section{Appendices}

\section{Appendix A: Advertisements tested}

ANIMALS: Cow

\section{(Q) Mercy For Animals $\bullet$}

Sponsored $\cdot$ (2)

Most farmed cows in the U.S. live at factory farms, where they suffer mistreatment and painful physical abuse.

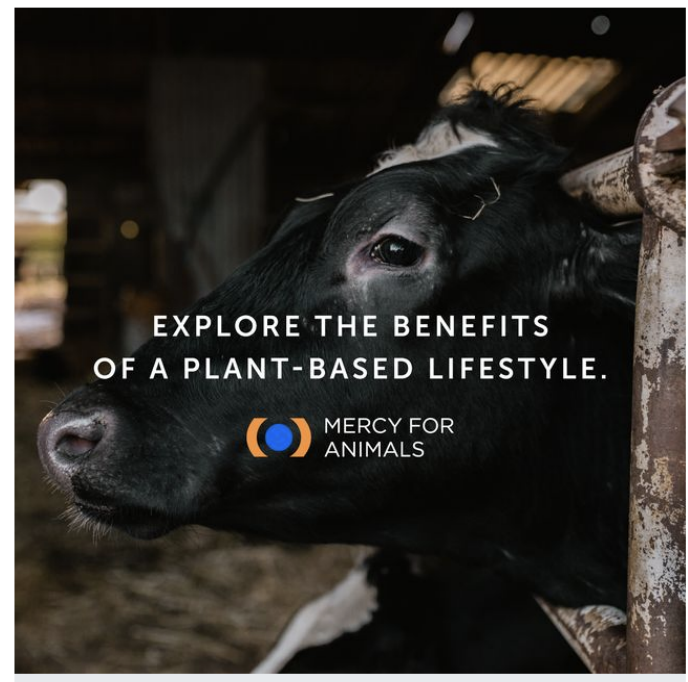

FORM ON FACEBOOK Cows Suffer at Factory Farms

\section{SIGN UP}

\section{ANIMALS: Pig}

(C) Mercy For Animals $\bullet$

Sponsored. A

Most farmed pigs in the U.S. live at factory farms, where they suffer mistreatment and painful physical abuse.

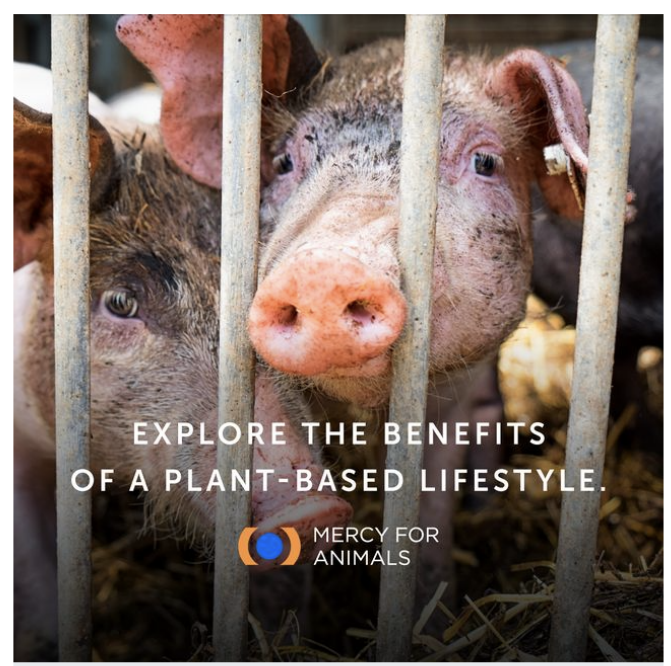

FORM ON FACEBOOK Pigs Suffer at Factory Farms
SIGN UP
ANIMALS: Fish

Mercy For Animals $\bullet$ Sponsored $\cdot$ e

Most farmed fish in the U.S. live at factory farms, where they suffer mistreatment and painful physical abuse.

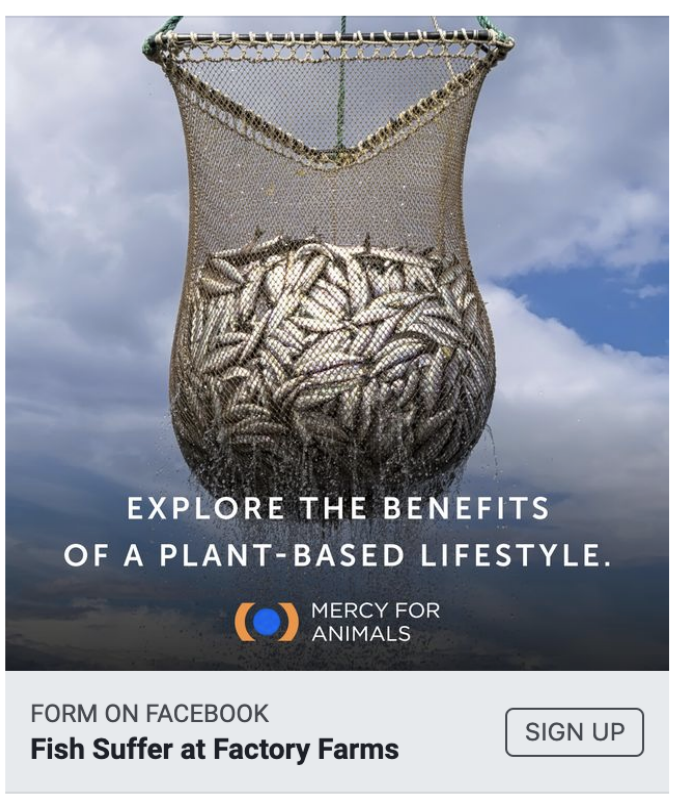

\section{ANIMALS: Chicken}

(C) Mercy For Animals $\bullet$ Sponsored. (A)

Most farmed chickens in the U.S. live at factory farms, where they suffer mistreatment and painful physical abuse.

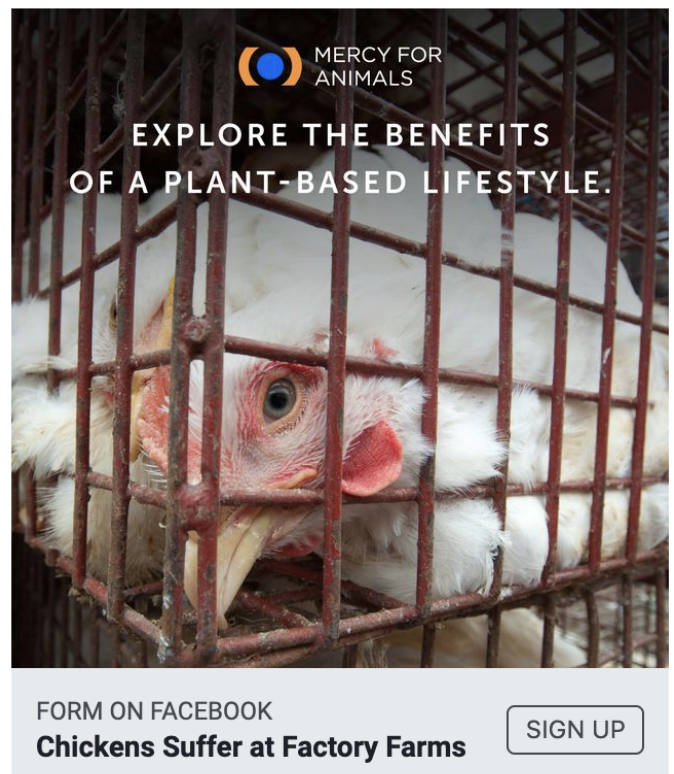




\section{HEALTH: Pathogens}

(O) Mercy For Animals $\bullet$

Sponsored $\cdot \theta$

Studies show that meat and other animal products are major carriers of Salmonella, Campylobacter, and E. coli.

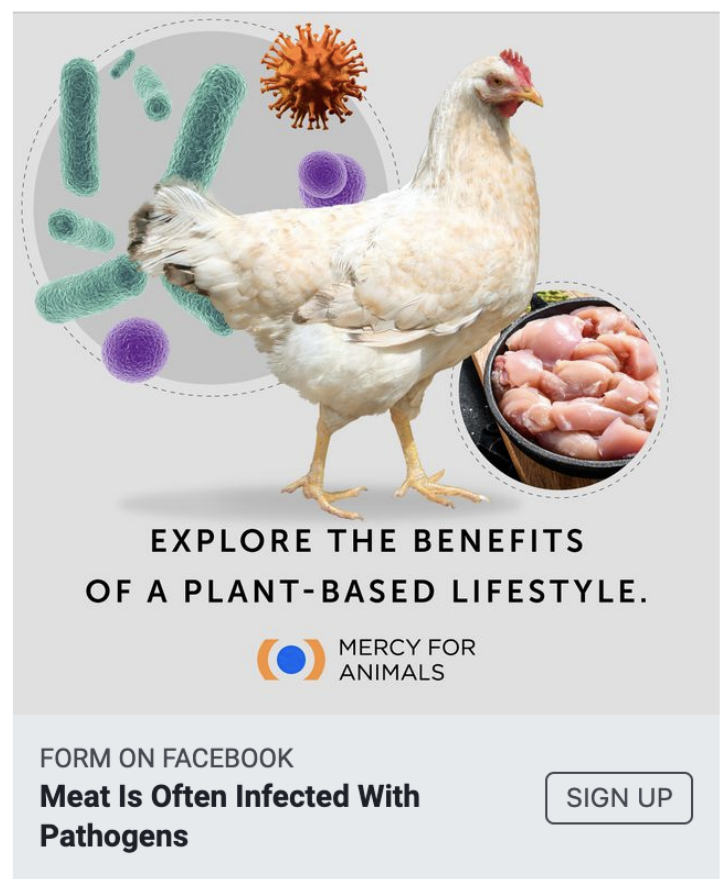

\section{HEALTH: Chronic disease}

(O) Mercy For Animals $\odot$ Sponsored $\cdot(A)$

Studies show that red and processed meat increase the risk of heart disease and cancer.

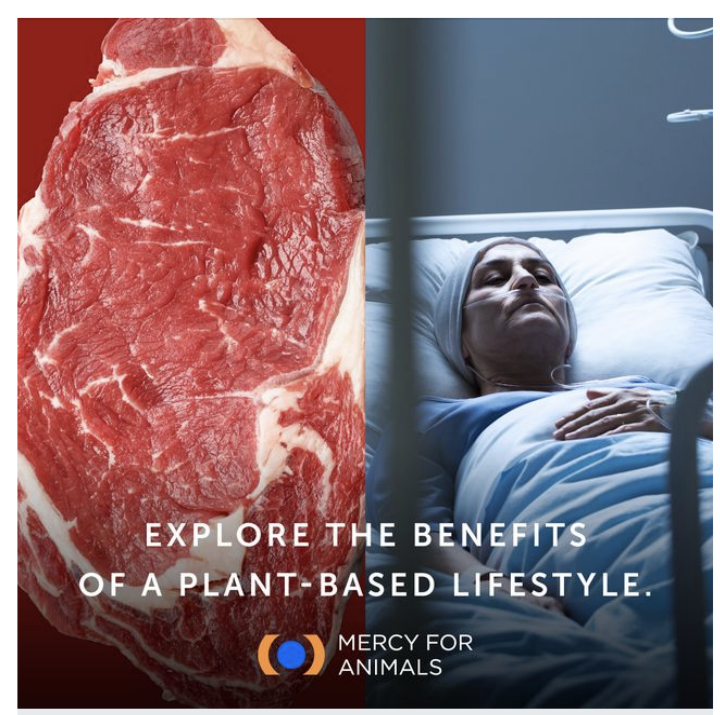

FORM ON FACEBOOK Meat Raises Risks of Chronic Disease

\section{HEALTH: Antibiotics} Mercy For Animals $\bullet$
Sponsored $\cdot \theta$

Because of antibiotic misuse in farming, animal products are often contaminated with antibioticresistant pathogens.

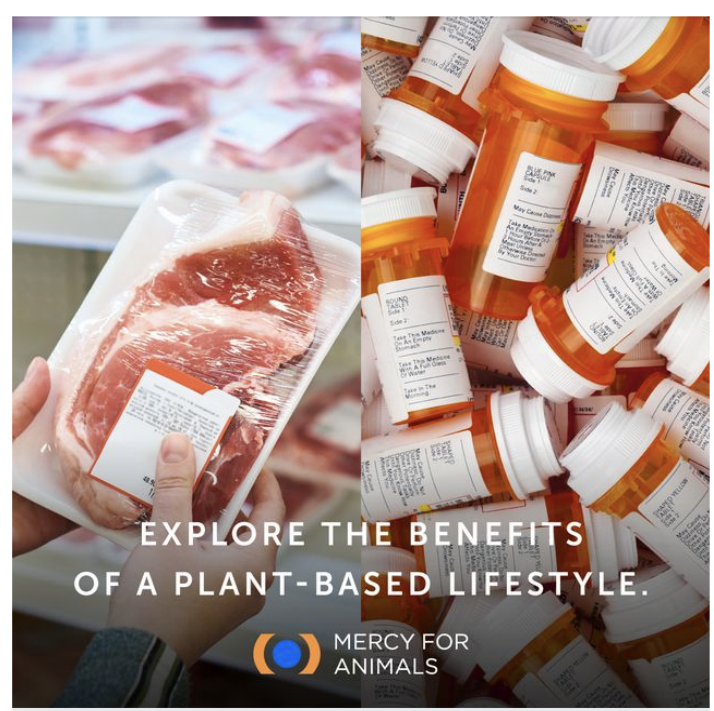

FORM ON FACEBOOK

Meat Is Often Infected With

SIGN UP

\section{HEALTH: Obesity}

(O) Mercy For Animals $\bullet$ Sponsored. (A)

Studies show that high meat consumption is associated with increased BMI, waist circumference, and obesity rates.

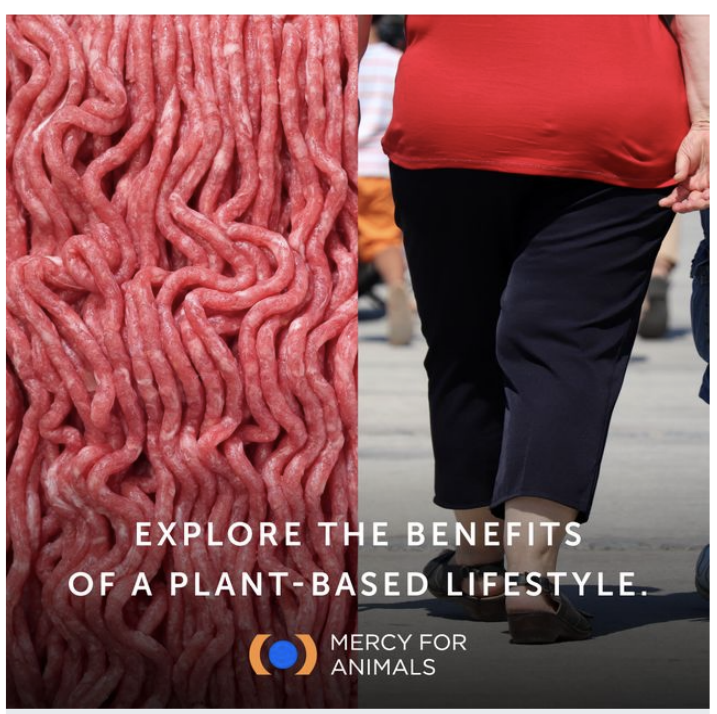

FORM ON FACEBOOK Meat Is Associated With Obesity
SIGN UP 


\section{ENVIRONMENT: Wastes water}

(O) Mercy For Animals $\bullet$

Sponsored. (2)

Animal agriculture is a major drain on fresh water worldwide, directly contributing to water shortages.

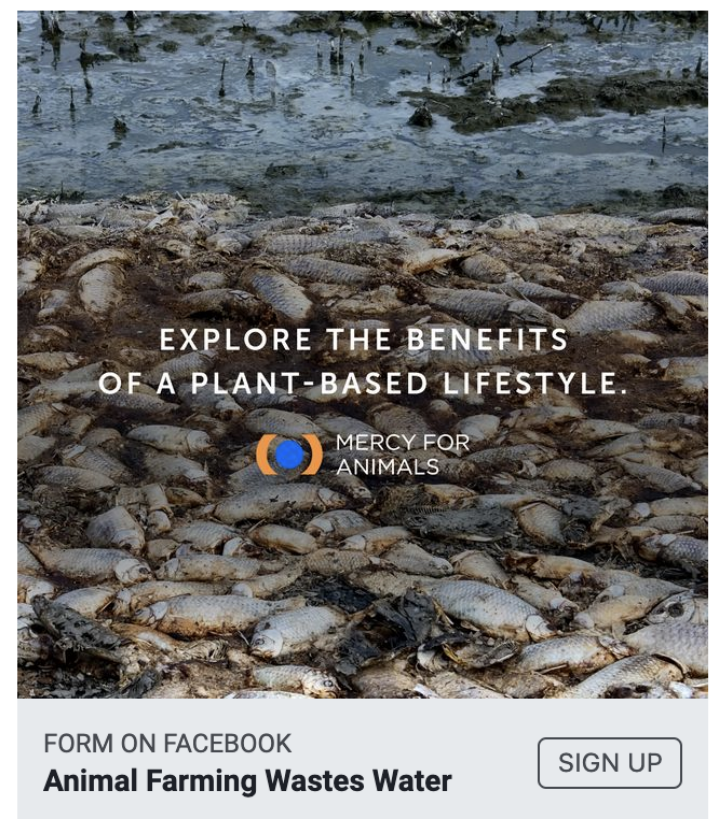

ENVIRONMENT: Deforestation

(O) Mercy For Animals •

Sponsored. A

Animal agriculture is a major cause of land-use change worldwide, directly contributing to deforestation and habitat destruction.

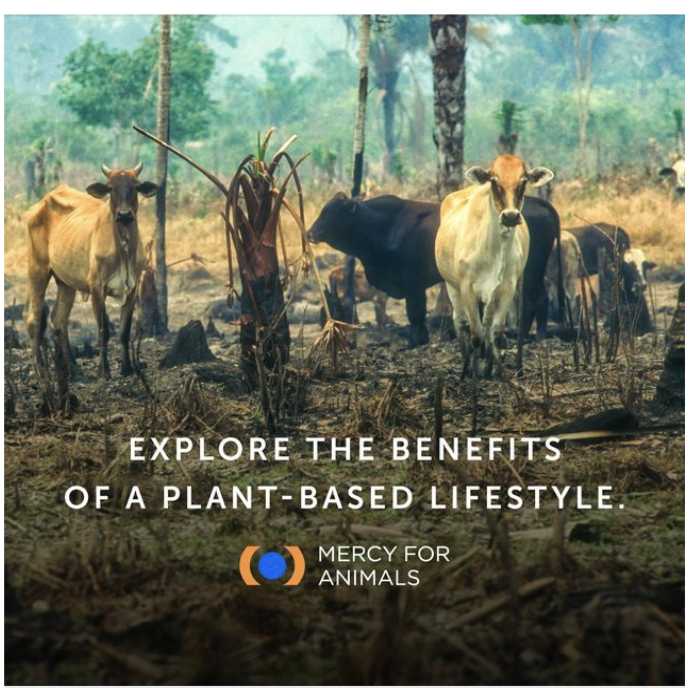

FORM ON FACEBOOK

Animal Farming Drives

SIGN UP

\section{ENVIRONMENT: Climate change}

(O) Mercy For Animals $\bullet$

Sponsored.

Animal agriculture is a major source of greenhouse gas emissions worldwide, directly contributing to climate change.

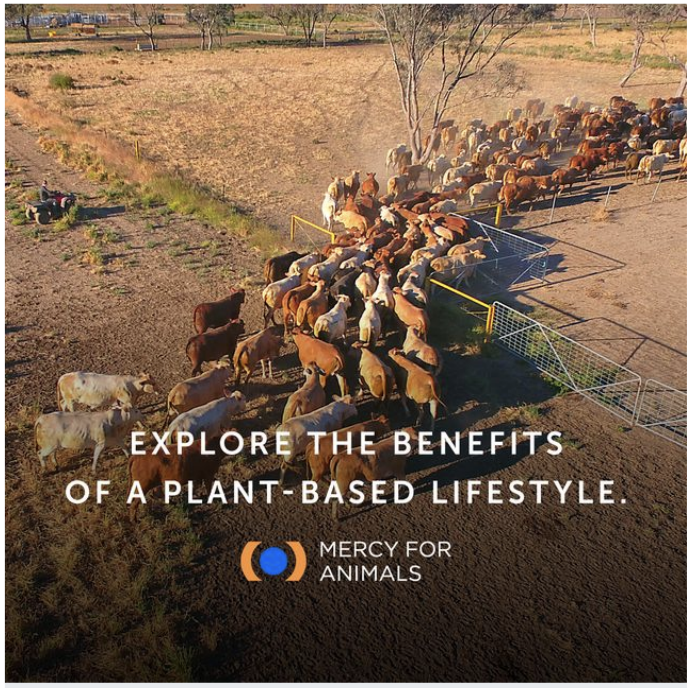

FORM ON FACEBOOK

Animal Farming Causes Climate Change

\section{SOCIAL: Social norm}

(O) Mercy For Animals $\bullet$

Sponsored. $\cdot 2$

As more people switch to meat and dairy alternatives, plant-based diets are more popular than ever before in the US.

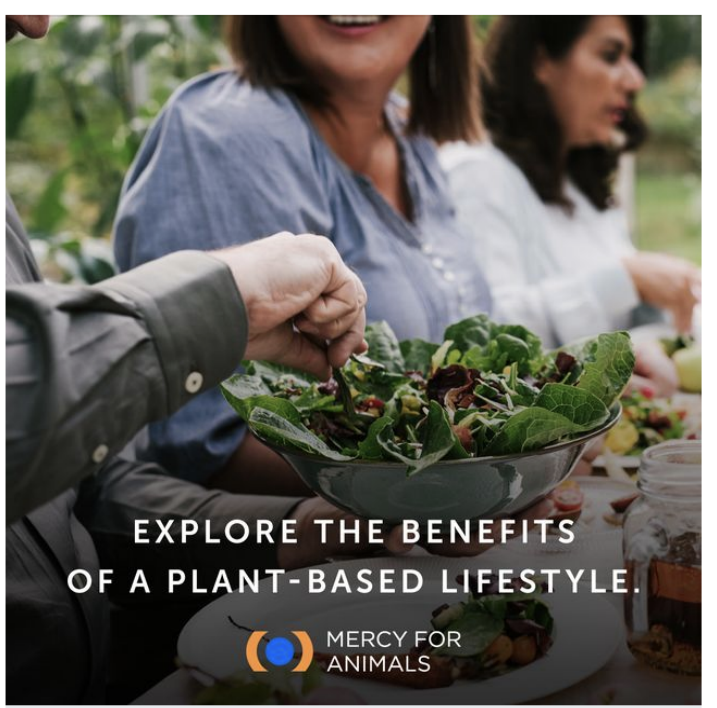

FORM ON FACEBOOK

More and More People Now Eat SIGN UP Plant-Based 